\title{
CRISTO: O FUNDAMENTO DA \\ INTERIORIDADE NO ITINERARIUM \\ MENTIS IN DEUM, DE SÃO BOAVENTURA
}

\author{
Christ: the fundament of interiority in \\ Itinerarium Mentis in Deum, of Saint Boaventura
}

\author{
Ricardo José Bellei
}

\section{RESUMO}

O presente trabalho analisa o fundamento da interioridade na obra Itinerarium Mentis in Deum (Itinerário da mente para Deus, 1259) escrita por São Boaventura (1217-1274). Na concepção do autor, a interioridade é um itinerário para o conhecimento da verdade. E é no mais profundo de si que a alma encontra não só a si mesma, mas o Verbo interior, o Cristo, o fundamento e sentido da interioridade.

Palavras-chave: Cristocentrismo. Interioridade. São Boaventura. Verdade.

\section{ABSTRACT}

This work analyzes the foundation of interiority in writings Itinerarium Mentis in Deum (The Mind's Road to God, 1259) written by St Bonaventure (1217-1274). For him, interiority is an itinerary for the knowledge of truth. And it is more profound themselves that the soul is not only to itself, but the verb interior, the Christ, the fundament and a sense of interiority.

Keywords: Christocentrism. Interiority. Saint Bonaventure. Truth.

\begin{tabular}{|l|l|l|l|l|l|}
\hline Teocomunicação & Porto Alegre & v. 44 & n. 2 & p. 247-260 & maio-ago. 2014 \\
\hline
\end{tabular}




\section{Introdução}

Para Francesco Petrarca (1304-1374) - um dos mestres do Humanismo italiano - os séculos que o precederam eram denominados, ironicamente, de tenebrae, "tenebrosos, escuros". Esta, porém, não era uma atitude isolada: com o advento do século XVI, os pensadores expressavam um desprezo vigoroso pelos 10 séculos que os separavam do período áureo da gloriosa Antiguidade Clássica. Assim, tudo o que se situava nesse período que separava os dois pontos altos da criatividade humana - a Antiguidade e o Renascimento - foi [sendo] considerado um intervalo, um tempo intermédio, uma Idade Média. O jocoso desdém de Petrarca transformou-se em uma "verdade" comumente aceita e repetida e a expressão "Idade Média" passou a simbolizar os 1.000 anos em que, no mundo, nada de bom ocorreu. Ao contrário: esse seria o período das torturas, do obscurecimento da inteligência, do eclipse da razão.

Felizmente, em todos os grandes centros de cultura se dá, hoje, especial destaque ao estudo da Idade Média. Longe vai o tempo em que se falava a sério do "obscurantismo medieval", e era sinal de "sabedoria", a propósito desse período, um desprezo tão imperante como burlesco. Sejam quais forem os julgamentos que se formem sobre a abrangência e a valia das especulações dos doutores medievos, ninguém, com o mínimo de conhecimento histórico, atreve-se a contestar a necessidade e o benefício de se aprofundar num amplo período que tanto enriqueceu a civilização universal, uma vez que "se há hoje uma Filosofia como tal, é ao paciente trabalho dos pensadores medievais que a devemos", ${ }^{1}$ pois "pesquisar a Idade Média é, de certo modo, trabalhar no cartório onde se encontra a certidão de nascimento do Ocidente". ${ }^{2}$

O século XIII é considerado o vértice do Medievo, e as grandes sínteses doutrinais que este período produziu são os frutos mais preciosos do vasto movimento de idéias que se conhece sob o nome de Escolástica. Uma destas sínteses é a denominada Escola Franciscana, "que trata daquela corrente filosófica na qual se enquadram os diversos pensadores da Ordem dos Frades Menores". ${ }^{3}$ São Boaventura, ${ }^{4}$ cognominado

1 GILSON, Etienne. A filosofia na Idade Média. São Paulo: Martins Fontes, 1998, p. 629.

2 ULLMANN, Reinhold Aloysio. A universidade medieval. Porto Alegre: EDIPUCRS, 2000, p. 13.

3 DE BONI, Luis Alberto. A Escola Franciscana: de Boaventura a Ockham. Revista Veritas, PUCRS, v. 45, n. 3 , set. 2000, p. 317.

4 São Boaventura nasceu em Civita, hoje distrito de Bagnoregio, na Itália, em meados de 1217-1218. Após ingressar na Ordem Franciscana, legou à posteridade vasta obra intelectual. Eleito Ministro Geral da Ordem Franciscana, empenhou-se tão profundamente 
Doutor Seráfico, é considerado um dos ilustres representantes dentre os vários mestres da Escola Franciscana. Além de um dos professores mais celebrados da Universidade de Paris, foi também Ministro Geral da Ordem Franciscana, pregador popularíssimo, cardeal e bispo, organizador do Concílio de Lyon (1274) e legado pontifício junto ao mesmo Concílio. Suas contribuições para a Filosofia, Teologia e Mística são ricas fontes onde inúmeros pensadores foram buscar inspiração. ${ }^{5}$

Exímio representante da corrente agostiniana, Boaventura compreendeu que Deus é a realidade intimamente presente e cognoscível à alma humana sem ser, porém, a ela imanente. A alma, embora infinitamente próxima de Deus, é uma criatura e, por isso mesmo, não pode ter a mesma natureza do Criador. Dessa forma, como poderá, portanto, unir-se com Deus? Boaventura revelou que só o conhecimento de si mesmo pode elevar o homem ao conhecimento de Deus, descobrindo, no próprio ser da alma, estampada à sombra da imagem divina. Mas como se dá essa descoberta? Neste trabalho, procura-se esclarecer de que forma a interioridade, em São Boaventura, é a via de acesso a Deus, o itinerário da mente até Deus.

\section{O Itinerarium Mentis in Deum 6}

São Boaventura escreveu o Itinerário da Mente para Deus Itinerarium Mentis in Deum - no ano de 1259, junto a um retiro realizado

em reestruturá-la que recebeu o epíteto de segundo fundador da Ordem. Faleceu em 15 de julho de 1274 e foi canonizado em 1482. Foi elevado ao número dos doutores da Igreja em 1587.

5 "Descobre-se cada vez com mais clareza por detrás de São Boaventura uma série de pensadores cuja obra consistiu principalmente em manter, aprofundar e desenvolver os princípios metafísicos sobre os quais sua doutrina estava fundada. Mateus de Aquasparta, João Peckham, Eustáquio de Arrás, Guilherme de la Mare, Gauthier de Bruges, Pedro de João Olivi, receberam em distintos graus sua influência e prepararam as novas sínteses doutrinais do século XIV, e, acima de todos, Duns Scoto. (...) Toda a obra de Raimundo Lúlio é completamente ininteligível, se se faz abstração do simbolismo de São Boaventura e de sua doutrina das iluminações intelectuais e morais. Para João Gerson, esta influência doutrinal se estende ao domínio da espiritualidade moderna; invadirá e ocupará durante séculos a consciência cristã, e creio que não seria absurdo estudar se o que chamamos escola francesa de espiritualidade não deriva, em parte ao menos, da escola franciscana de espírito bonaventuriano". In: GILSON, Etienne. La filosofia de San Buenaventura. Trad. Esteban de Zuraire, Colección Thau. Buenos Aires: Editorial Desclée de Brouwer, 1948, p. 465-466.

6 São Boaventura: Itinerarium Mentis in Deum. In: DE BONI, Luis Alberto. Obras escolhidas de São Boaventura. Porto Alegre: Coedição EST, SULINA e UCS, 1983, p. 163-203. [Organização de Luis Alberto de Boni e tradução de Jerônimo Jerkovic]. Doravante as referências a esta obra de São Boaventura usarão a sigla: Itin., e as citações, bem como a numeração das páginas, seguirão o mesmo texto. 
no Monte Alverne. Nessa obra, densamente adornada de conceitos filosófico-teológicos e místicos, Boaventura pretendeu mostrar que toda ação humana, todo vigor intelectual direciona-se para a finalidade última do homem: a união com Deus, da qual emerge aquela paz que ultrapassa todo sentimento. ${ }^{7}$ A seguir, serão feitas considerações importantes acerca do título da obra. Tais considerações são pertinentes, pois revelam a profundidade das palavras escolhidas por São Boaventura.

"Itinerário" vem do latim itinerarium, itinerarii que, por sua vez, remete a iter, itineris. ${ }^{8}$ Em sua etimologia, iter, itineris é um substantivo neutro e significa, primeiramente e em sentido próprio, "percurso", "caminho percorrido", "marcha", "viagem". Em segundo lugar, significa, "estrada", "caminho", "passagem". E, em sentido figurado, significa, "via", "meio", "maneira". São Boaventura, perpassando por todos estes significados, justificou o uso dessa palavra para evidenciar que Itinerarium é a descrição da odisseia humana até a imersão em Deus. No contexto do Itinerarium, deve-se entender que a afirmação bonaventuriana da presença de Deus no homem interior não representa a nobreza da alma por ela mesma, mas que, para tornar-se verdadeiramente digna de ser morada da Verdade, a alma deve converter-se em interioridade, isto é, em imagem de Deus.

A estrutura do Itinerarium é permeada de imagens e alegorias metafóricas ${ }^{9}$ e segue o simbolismo das asas do Serafim ${ }^{10}$ descrito no livro de Isaías: "cada um deles (Serafins) tinha seis asas; com um par velavam a face; com outro cobriam os pés; e, com o terceiro, voavam". ${ }^{11}$ Desta forma, os dois primeiros capítulos da obra dedicamse à reflexão sobre o mundo sensível; o terceiro e o quarto, à meditação da alma sobre si mesma; o quinto e o sexto, à contemplação do Transcendente.

7 Itin., Prólogo, n. 1, p. 165: "pacis illius, quae exuperat omnem sensum".

8 CUNHA, Antônio Geraldo da. Dicionário etimológico Nova Fronteira da língua portuguesa. 2. ed. Verbete: itinerário. Rio de Janeiro: Nova Fronteira, 2005, p. 450.

9 "O simbolismo permeia e resume toda a obra de S. Boaventura", cf: PIAZZA, Leonardo. Mediazione simbolica in San Bonaventura. Vicenza: Edizioni L.I.E.F., 1978, p. 11.

${ }^{10}$ Segundo o Catolicismo, Serafins são anjos que têm como "tarefa principal adorar e servir junto ao trono de Deus" (cf. HEINZ-MOHR. Dicionário dos símbolos - imagens e sinais da arte cristã. Verbete Anjos. São Paulo: Paulus, 1994, p. 24).

${ }^{11}$ Is, 6, 2: "seraphin stabant super illud sex alae uni et sex alae alteri duabus velabant faciem eius et duabus velabant pedes eius et duabus volabant". 
Em forma esquemática, a composição do Itinerarium é a seguinte:
$\left\{\begin{array}{l}\text { Primeira via } \\ \text { Segunda via } \\ \text { Terceira Via }\end{array}\right.$
a) mediante omundo sensível: contemplarDeus através do vestígio.
b) no mundo sensível: contemplar Deus no vestígio.
a) mediante a alma.
b) na alma.
a) mediante a ideia do Ser.
b) na meditação do Bem.

A meditação do mundo sensível conduz o pensamento a descobrir Deus fora do homem; a reflexão da alma sobre si mesma leva o intelecto a descobrir Deus dentro de si; e a contemplação do Transcendente incita o entendimento a atingi-Lo acima de si próprio.

Segundo esta tríplice maneira de nos elevarmos progressivamente a Deus, a nossa alma possui três principais vias para perceber. Na primeira, olha sobre as coisas corporais e exteriores pelo que se chama 'animalidade' ou sensitividade. Na segunda, olha sobre si mesma e dentro de si mesma - e se chama, por isso, espírito. Na terceira, olha acima de si mesma - e se denomina então mente. $^{12}$

Ainda no título, Boaventura destaca a palavra mentis, genitivo latino de 'mens', que "designa a parte superior do espírito, precisamente aquela na qual se encontra a imagem de Deus". ${ }^{13}$ Para bem se entender isso, é preciso frisar que Boaventura, seguindo Santo Agostinho, compreende que a alma humana é dividida em duas partes: inferior e superior. A primeira liga-se ao mundo sensível e a segunda - a porção mais nobre da alma, denominada mens - é onde se dá

\footnotetext{
${ }^{12}$ Itin., cap. I, n. 4, p. 168: "Secundum hunc triplicem progressum mens nostra tres habet aspectus principales. Unus est ad corporalia exteriora, secundum quem vocatur animalitas seu sensualitas: alius intra se et in se, secundum quem dicitur spiritus; tertius supra se, secundum quem dicitur mens".

13 “'Mens' désigne la partie supérieure de l'esprit, précisément celle dans laquelle se trouve l'image de Dieu". (BOUGEROL, Jacques-Guy (Org.). Lexique Saint Bonaventure. Paris: Éditions Franciscaines, 1969, p. 98 (tradução nossa).
} 
o conhecimento de Deus ou onde se pode conhecê-Lo e amá-Lo. No entanto, a alma humana é mens não por força própria, mas por obra de Deus, que a torna capax Dei (capaz de Deus). Portanto, é a mens que, guiada pela luz da verdade divina, completa seu itinerário até Deus.

Mais ainda, de acordo com o sistema gramatical de declinações latinas, a preposição "in", rege, em latim, ora acusativo, ora ablativo. Quando rege acusativo, é empregada com verbos que indicam movimento. Dessa forma, Boaventura explicita sua mística: a união do homem com Deus se dá com um movimento, com um "mergulho" em Deus.

São Boaventura não diz ' $a d$ ', porque a meta do Itinerarium não é levar meramente até Deus, nem somente para tocá-lo ou alcançá-lo pela inteligência. 'In' significa o movimento atual para entrar em Deus na mais sublime afeição do amor pela união mística. ${ }^{14}$

A noção de movimento, essencialmente relacionada à interioridade, é essencial, pois representa um empenho da alma em procurar a verdade, sendo que esse esforço, necessariamente, deve passar por um itinerário para dentro de si mesmo. Esse percurso, porém, não se reveste de um caráter egoístico, uma vez que, na mais profunda interioridade da alma, o homem encontrará o próprio Deus que o criou. Percebe-se que o anseio de São Boaventura é ensinar que todo o conhecimento humano - seja filosófico ou teológico - deve tornar-se uma "elevatio mentis in Deum" - elevação da mente até Deus. Portanto, o homem é capax Dei e Deus é a realidade intimamente presente e cognoscível à alma humana, sem ser, porém, a ela imanente. A alma é, assim, o habitáculo onde "resplandece a imagem da beatíssima Trindade" ${ }^{15}$ A semelhança, não igualdade, da alma com o Criador é o fundamento e o sentido da interioridade, pois somente o conhecimento de si mesmo pode elevar o homem ao conhecimento de Deus, descobrindo, estampada no próprio ser da alma, a sombra da imagem divina. A interioridade é, portanto, a via de acesso a Deus, o itinerário da mente até Deus.

\footnotetext{
${ }^{14}$ BOUGEROL, op. cit., p. 86, tradução nossa.

${ }^{15}$ Itin., Cap. III, n. 1, p. 181.
} 


\section{O sentido da interioridade}

Para Boaventura, a natureza intelectual foi criada "apta para o repouso da contemplação". ${ }^{16}$ Esta é uma atividade que auxilia a inteligência a considerar, em primeiro lugar, a existência atual das coisas e a reconhecer nelas o sumo poder do Criador, a sua sabedoria e a sua bondade que resplandecem no mundo sensível; em segundo lugar, a contemplação auxilia o intelecto a vislumbrar os reflexos da Trindade resplandecendo na alma; por fim, eleva a razão acima do plano sensível, mergulhando a mente no esplendor da luz da eterna Verdade, o Ser e o Bem.

No entanto, a corporeidade, propensa ao imediato e ao contingente, obnubila a capacidade de perceber a infinita proximidade de Deus à alma. ${ }^{17} \mathrm{E}$, "assim, [a alma] toda imersa nas coisas sensíveis, torna-se impotente para encontrar em si mesma a imagem de Deus". ${ }^{18} \mathrm{O}$ esforço de São Boaventura está em conduzir o raciocínio da exterioridade para a interioridade, para que este reconheça que seu objeto natural é a totalidade do ser, o próprio Deus. A interioridade bonaventuriana reside na relação da alma com ela mesma e com Deus na pessoa do Cristo.

Ora, "a perfeição da natureza requer que o homem conste simultaneamente de corpo e alma, como de matéria e forma, que possuem inclinação e necessidade recíproca". ${ }^{19}$ No entanto, a alma, embora anseie unir-se ao corpo para comunicar-lhe suas perfeições, é uma substância completa, espiritual e que subsiste em sim mesma. Compreende-se, assim, a superioridade metafísica da alma em relação ao corpo, uma vez que aquela opera como princípio regulador deste. Dessa forma, é na alma, e pela alma, que se pode atingir o conhecimento da verdade. Há aqui uma clara oposição ao platonismo, para quem a verdade reside num mundo exterior à alma, isto é, no Mundo das Ideias.

Seguindo a tradição cristã, o autor acentua a dependência ontológica da criatura com relação ao Criador, baseando esta dependência na frase

${ }^{16}$ Itin., cap. I, n. 7, p. 169: "Secundum enim primam naturae institutionem creatus fuit homo habilis ad contemplationis quietem".

${ }^{17}$ Itin., cap. IV, n. 1, p. 187: "Mirum autem videtur (...) quod Deus sit ita propinquus mentibus nostris, quod tam paucorum est in se ipsis primum principium speculari”.

${ }^{18}$ Idem, ibidem: "Ideo totaliter in his sensibilibus iacens, non potest ad se tanquam ad Dei imaginem reintrare", (acréscimo nosso).

${ }^{19}$ BOAVENTURA, São. Brevilóquio, parte VII, cap. 5, n. 2, p. 275, In: DE BONI, Luis Alberto. Obras Escolhidas ..., op. cit., p. 63-288. 
de Cristo: "Sem mim, nada podeis fazer". ${ }^{20}$ Dessa forma, a própria interioridade é um dom de Deus, ou seja, até para entrar em si mesmo, para conhecer-se a si próprio, o homem necessita do Mestre interior, uma vez que "ninguém, por mais iluminado que esteja pelas luzes da razão e pelo estudo das ciências, pode entrar em si mesmo para 'deleitarse no Senhor', se não for por meio de Jesus Cristo que disse: - Eu sou a porta". ${ }^{21}$ É justamente neste item que reside o sentido da interioridade bonaventuriana: a relação da alma com ela mesma e com Deus se dá por meio de Cristo.

\section{Cristo, o centro da história}

É impossível compreender o Ocidente medieval desatrelado, principalmente, da Teologia Católica. As considerações a seguir perpassam por esse contexto e são de extrema necessidade para a correta compreensão do pensamento do autor.

A tese principal bonaventuriana é a compreensão da figura de Cristo como centro da história. Para ele, Cristo é, simultaneamente, Deus e o próximo, o irmão e o Senhor, o Rei e o amigo, o Verbo encarnado e o Verbo incriado, o Criador e o Redentor, o ponto Alfa e o Ômega. ${ }^{22}$ Dessa forma, Cristo é sempre o centro e o ponto de virada da história, que se divide em antes e depois d'Ele. Por meio de Cristo, a história se completa, pois é Cristo quem mostra as vias da Providência Divina para a redenção e santificação do ser humano. No Franciscanismo, a encarnação do Verbo de Deus adquire uma importância única e absoluta, não admitindo comparação com nenhum outro acontecimento. Portanto, esta maneira de compreender a história permite que se entenda o cerne da querela entre os seguidores da filosofia agostiniana e os adeptos do pensamento aristotélico, uma vez que o problema da criação ou da eternidade do mundo estava em questão. São Boaventura seguiu o agostinismo e rejeitou vigorosamente os pensadores cristãos que

${ }^{20}$ Jo, 15,5: "sine me nihil potestis facere".

${ }^{21}$ Itin., cap. IV, n. 2, p. 188: “Ao mesmo tempo, nosso Deus e nosso próximo, nosso irmão e nosso Senhor, nosso Rei e nosso amigo, o Verbo encarnado e o Verbo incriado, nosso Criador e nosso Redentor, nosso Alfa e nosso Ômega". "Ideo, quantumcumque sit illuminatus quis lumine naturae et scientiae acquisitae, non potest intrare in se, ut in se ipso delectetur in Domino, nisi mediante Christo, qui dicit: Ego sum ostium".

22 Itin., cap. IV, n. 5, p. 190: "Qui simul est proximus et Deus, simul frater et dominus, simul etiam rex et amicus, simul Verbum increatum et incarnatum, formator noster et reformator, ut alpha et omega". 
adotaram uma postura racionalista e se ensoberbeceram com uma filosofia autossuficiente, afastada da fé e da teologia.

Para o Doutor Seráfico, a Providência Divina conduz a história e a filosofia se subordina à sabedoria cristã, uma vez que Cristo, como Verbo, é, ao lado de Deus, quem delineia os planos da história, pois é "o Alfa e o Ômega, a causa e o efeito, o Criador e a criatura". ${ }^{23}$ Além disso, Cristo, como Verbo inspirado, revela os planos da história, pois "'ilumina todo homem que vem a este mundo', o qual é 'a verdadeira Luz". ${ }^{24}$ E Cristo, como Verbo encarnado, concretiza e conclui o mistério da salvação: "o Ser puríssimo e absoluto - isto é, o Ser por excelência - é o primeiro e o último. Por isso é a origem de todas as coisas e o fim que as consuma". ${ }^{25}$

É notório que a concepção da história, em São Boaventura, é circular, mas não cíclica, pois a história origina-se de um ponto inicial e a ele retorna. ${ }^{26} \mathrm{O}$ tempo da história é concedido ao homem para que este ascenda a Deus, mediante a razão, mas através de Cristo, pois "ele é o caminho, é o mestre e o princípio do conhecimento". ${ }^{27}$ Cristo plenifica e é o centro dos tempos e da história, além de ser o arquétipo de toda a criação, pois todas as criaturas procederam do Artífice Supremo (Deus) por meio do Verbo Eterno (Cristo). Dessa forma, "todas as coisas são d'Ele, por Ele e n'Ele"' 28 e o mundo criado é, na concepção bonaventuriana, a escada pela qual o homem se eleva até o Criador, ${ }^{29}$ porque toda a criação assemelha-se a um livro aberto onde Deus se desvenda à inteligência humana. Todo o universo criado é como que uma sala adornada de espelhos que refletem o poder, a sabedoria e a bondade divinas.

${ }^{23}$ Itin., cap. VI, n. 7, p. 200: "Alpha et omega, causatum et causam, Creatorum et creaturam".

${ }^{24}$ Itin., cap. III, n. 3, p. 183: "Quae illuminat omnem hominem venientem in hunc mundum, quae est lux vera".

${ }^{25}$ Itin., cap. V, n. 8, p. 195: "Quia igitur esse purissimum et absolutum, quod est simpliciter esse est primarium et novissimum".

26 “A visão bonaventuriana da história é circular (não cíclica), tendo o círculo um ponto inicial, ao qual, realizado o movimento perimetral, encosta-se o ponto final: a história procede de um ponto primeiro e volta a ele, sendo seccionada entre a partida e a chegada pela presença de Cristo", in DE BONI, Luis Alberto. Obras Escolhidas de São Boaventura..., op. cit., p. 37.

${ }^{27}$ BOAVENTURA, São. Cristo, Único Mestre de Todos. Trad. Luis de Boni, In: DE BONI, Luis Alberto, org.. Obras Escolhidas..., op. cit., p. 221: "Christus namque secundum quod via est magister et principium cognitionis".

${ }^{28}$ Itin., cap. V, n. 8, p. 196: "Ac per hoc, ex ipso et per ipsum et in ipso sunt omnia et hoc".

${ }^{29}$ Itin., cap. I, n. 2, p. 168: "Cum rerum universitas sit scala ad ascendendum in Deum". 
Ora, as criaturas do mundo visível são os sinais das perfeições invisíveis de Deus: seja porque Deus é a sua causa, seu exemplar e seu fim (pois todo efeito é sinal de sua causa, toda cópia é sinal de seu exemplar e todo meio é sinal do fim ao qual conduz), seja por meio de sua própria representação, seja como figuras proféticas, seja pelo ministério dos anjos, seja por uma instituição divina.

Todas as criaturas são, de fato, pela sua natureza, uma imagem ou uma semelhança da Sabedoria eterna. ${ }^{30}$

\section{Cristo, $o$ fundamento da interioridade, no Itinerarium}

Para o Franciscanismo, o mistério da Encarnação de Jesus é o ápice máximo de toda obra divina da Criação, pois é o ponto de reviravolta da relação entre o homem e Deus. Nesse acontecimento único e singular, o Criador, ao assumir a condição humana na pessoa de Cristo, deu à interioridade uma nova configuração: Deus não usará apenas recursos exteriores como anjos, profetas ou visões para se comunicar com o ser humano, mas o diálogo se dará, sobretudo, a partir do interior, numa comunicação entre Deus e a alma, mediante o Verbo, que ensina interiormente. A alma é, para São Boaventura, o templo vivo onde se dá a relação ontológica entre o Criador e a criatura.

Com a Encarnação, o próprio Cristo afirmou que o homem nada pode por si só e sequer se encontra consigo mesmo e se eleva a Deus senão através d'Ele mesmo, o próprio Exemplar divino. ${ }^{31}$ É esse o motivo pelo qual São Boaventura apresenta a sua filosofia, afirmando que Deus, em sua unidade trinitária, é Causa eficiente, Causa exemplar e Causa final de toda a criação. Em virtude disso, a Trindade se revela como o ens fundamentale, ou principium originale de tudo o que existe. Deus, portanto, é a origem da Verdade e nenhuma coisa criada pode ser verdadeira por sua própria essência, mas se torna verdadeira por participação à Verdade divina.

\footnotetext{
${ }^{30}$ Itin., cap. II, n. 12, p. 179-180: "Significant autem huiusmodi creaturae huius mundi sensibilis invisibilia Dei, partim quia Deus est omnis creaturae origo, exemplar et finis, et omnis effectus est signum causae, et exemplatum exemplaris, et via finis, ad quem ducit: partim ex propria repraesentatione; partim ex prophetica praefiguratione; partim ex angelica operatione; partim ex superaddita institutione. Omnis enim creatura ex natura est illius aeternae sapientiae quaedam effigies et similitudo".

${ }^{31}$ Cf. Jo 14, 6 "Jesus lhe respondeu: Eu sou o caminho, a verdade e a vida; ninguém vem ao Pai senão por mim" (dicit ei Iesus ego sum via et veritas et vita nemo venit ad Patrem nisi per me) e Jo 14, 11: "Crede-me: estou no Pai e o Pai em mim" (creditis quia ego in Patre et Pater in me est).
} 
No Itinerarium, Boaventura afirma que "o juízo se realiza segundo uma lei que faz abstração do tempo, do lugar e da mutabilidade - e, por isso mesmo, da dimensão, da sucessão e da mutação". ${ }^{32}$ Mas as coisas sensíveis que chegam ao intelecto são temporais, contingentes e mutáveis. Onde, portanto, encontrar estas condições que permitam um conhecimento seguro? As qualidades de imutabilidade, necessidade e eternidade só ocorrem em Deus. Assim, é a ação divina que confere sua imutabilidade aos objetos da mente e sua infalibilidade à inteligência, tornando o homem coparticipante da imutabilidade e infalibilidade que residem em Deus.

No pensamento bonaventuriano, o homem não pode conhecer nenhuma verdade sem o auxílio divino. Como Deus é a causa derradeira de todo ser, Ele é, igualmente, a causa do conhecimento humano e, sem Ele, nenhum conhecimento da verdade é possível, uma vez que "um saber seguro pressupõe a presença de um objeto imutável (...) e em todo conhecimento absolutamente certo, deparamos com algo de imutável, necessário e eterno". ${ }^{33}$ Dessa maneira, a alma humana possui, em si, de maneira inata, ${ }^{34}$ por ser imagem do Criador, a capacidade de alcançar Deus, mais ainda, de "mergulhar" em Deus nas "rationes aeternae", ${ }^{35}$ que não são dadas por um processo abstrativo, que vem de fora, mas sim somente através da interioridade.

A interioridade, longe de ser uma ação subjetiva do homem, é uma iniciativa da própria Verdade que motiva, impele e guia essa movimentação.

Nenhuma ciência, nem a Filosofia ou a Teologia podem tornar o homem verdadeiramente sábio: somente a graça de Cristo, o Verbo interior, é quem ilumina, eleva, amplia, purifica e aperfeiçoa o espelho da mens, uma vez que " ninguém, por mais iluminado que esteja pelas

32 Itin., cap. II, n. 9, p. 177-178: "Si enim diiudicatio habet fieri per rationem abstrahentem a loco, tempore et mutabilitate ac per hoc a dimensione, successione et transmutatione".

${ }^{33}$ Ibidem.

34 "Ao afirmar que o homem tem de Deus uma ideia inata, Boaventura não entende com isso que o homem possui uma visão imediata de quem seja Deus, uma intuição de Deus a modo do ontologismo; sua intenção é dizer que esse conhecimento é a possibilidade primeira na qual se realiza todo e qualquer conhecimento". In: DE BONI, Luis Alberto. Obras Escolhidas... op. cit., p. 50.

35 “As razões eternas são as ideias divinas que nos iluminam, regulam e estimulam nossa mente para the permitir alcançar o conteúdo absoluto e necessário do concreto, em uma interação da luz dessas ideias e a luz da nossa razão". (BOUGEROL, Lexique ..., op. cit., p. 112, tradução nossa). 
luzes da razão e pelo estudo das ciências, pode entrar em si mesmo para "deleitar-se no Senhor" se não for por meio de Jesus Cristo": ${ }^{6}$ apenas Cristo, o "Mediador entre Deus e os homens", ${ }^{37}$ centro de todas as coisas, é também, a interioridade da alma.

A interioridade é o caminho por excelência para o encontro com Cristo, o qual é a conexão válida para a compreensão da totalidade do conhecimento, além de ser o âmago da ordem ontológica, moral e histórica. Para Boaventura, Cristo é também o único meio lógico, epistemológico e metafísico pelo qual o conhecimento humano adquire plena certeza: lógico, enquanto pelos vestígios dispostos nas proporções e nos números presentes nas coisas corporais e sensíveis, o homem julga essas coisas de modo irrefutável, sendo conduzido, por elas, de modo evidente, à Sabedoria, isto é, à Imagem do Filho; ${ }^{38}$ epistemológico, enquanto aperfeiçoa e auxilia a mente, pela interioridade, nas leis do conhecimento e da filosofia racional, levando a inteligência à sabedoria do Verbo; ${ }^{39}$ metafísico, enquanto é modelo segundo o qual tudo foi feito, além de poder e sabedoria que tudo conserva e distingue. ${ }^{40}$

O homem procede de Deus, retorna a Ele e somente realizará o seu destino através de Deus. Mas esse itinerário do homem reflete o próprio itinerário da vida existencial de Cristo, o Verbo de Deus. Assim, a alma humana, no pensamento bonaventuriano, gravita em torno de Cristo, que "existe em todas as criaturas com seu poder, sua essência e sua presença, sem ser, porém, circunscrito por nenhuma delas". ${ }^{41}$ Dessa forma, apenas

\footnotetext{
${ }^{36}$ Idem, ibidem, p. 188: "Ideo, quantumcumque sit illuminatus quis lumine naturae et scientiae acquisitae, non potest intrare in se, ut in se ipso delectetur in Domino, nisi mediante Christo".

${ }^{37}$ Itin., cap. IV, n. 2, p. 188: "mediatoris Dei et hominum Iesu Christi".

${ }^{38}$ Itin., cap. II, n. 10, p. 179: "Cum igitur omnia sint pulcra et quodam modo delectabilia; et pulcritudo et delectatio non sint absque proportione; et proportio primo sit in numeris: necesse est, omnia esse numerosa; ac per hoc 'numerus est praecipuum in animo Conditoris exemplar' et in rebus praecipuum vestigium ducens in Sapientiam. Quod cum sit omnibus evidentissimum et Deo propinquissimum, propinquissime quasi per septem differentias ducit in Deum et facit, eum cognosci in cunctis corporalibus et sensibilibus, dum numerosa apprehendimus, in numerosis proportionibus delectamur et per numerosarum proportionunm leges irrefragabiliter iudicamus".

39 Itin., cap. III, n. 6, p. 185-186: "Nam omnis philosophia aut est naturalis, aut rationalis, aut moralis. Prima agit de causa essendi, et ideo ducit in potentiam Patris; secunda de ratione intelligendi, et ideo ducit in sapientiam Verbi; tertia de ordine vivendi, et ideo ducit in bonitatem Spiritus Sancti".

${ }^{40}$ Itin., cap. II, n. 9, p. 178: "per quam et secundum quam formantur formosa omnia (...) verum etiam cuncta conservans et distinguens".

${ }^{41}$ Itin., cap. I, n. 14, p. 172: "qui in cunctis rebus per potentiam, praesentiam et essentiam incircumscriptus existit".
} 
Cristo, a interioridade da alma, é a verdade plena que satisfaz totalmente a inteligência e o inquieto coração do homem.

\section{Conclusão}

A estrutura do Itinerarium de Boaventura mostra que a interioridade não é um exercício espontâneo da alma; é até mesmo um paradoxo, contrário à condição corporal, inclinada à materialidade, e, sobretudo, ao desejo de autossuficiência. Para recordar-se, portanto, de ser imagem e semelhança de Deus, a alma precisa mergulhar em si mesma e buscar, em sua interioridade, o que a diferencia de todos os outros seres da criação: a racionalidade. A principal característica do homem interior é, portanto, a vida racional. E essa vida racional será tanto mais perfeita quanto mais se aproximar do Verbo interior, para que Ele "ilumine os olhos de nossa mente" 42 e eleve a alma, "como por meio de um espelho, à contemplação da Santíssima Trindade"43, fruindo, deste modo, o espírito daquela paz "que ultrapassa todo entendimento"44.

Mediante a interioridade, a Verdade divina revela-se à razão como sendo o próprio Ser e o sumo Bem ${ }^{45}$, isto é, o Cristo, "o livro escrito por dentro e por fora" ${ }^{46}$ em quem Deus depositou a luz sobrenatural de sua divina sabedoria. ${ }^{47} \mathrm{E}$ esse livro, mais interior que a própria interioridade, só pode ser lido por aquelas almas que estejam ávidas da sabedoria divina e inflamadas do desejo de possuí-la, mas que queiram, sobretudo, dedicar-se a glorificar, admirar e degustar a Deus. ${ }^{48}$ Para São Boaventura, portanto, a interioridade converte-se em um pensar ou filosofar na fé.

\section{Referências}

BOUGEROL, Jacques-Guy (Org.). Lexique Saint Bonaventure. Paris: Éditions Franciscaines, 1969.

CUNHA, Antônio Geraldo da. Dicionário etimológico Nova Fronteira da língua portuguesa. 2. ed. Rio de Janeiro: Nova Fronteira, 2005.

42 Itin., Prólogo, n. 1, p. 165: "det illuminatos oculos mentis nostrae".

${ }^{43}$ Itin., cap. III, n. 5, p. 185: "Dum igitur mens se ipsam considerat, per se tanquam per speculum consurgit ad speculandam Trinitatem".

${ }^{44}$ Itin., Prólogo, n. 1, p. 165: "quae exuperat omnem sensum".

${ }^{45}$ Itin., cap. V, n. 3, p. 192-193 e cap. VI, n. 2, p. 197-198.

${ }^{46}$ Itin., cap. VI, n. 7, p. 200: "librum scilicet scriptum intus et extra".

${ }^{47}$ Itin., Prólogo, n. 4, p. 166: "sapientia divinitus inspirata".

${ }^{48}$ Ibidem: "sapientiae et eius desiderio inflammatis, vacare volentibus ad Deum magnificandum, admirandum et etiam degustandum". 
GILSON, Etienne. A filosofia na Idade Média. São Paulo: Martins Fontes, 1998.

DE BONI, Luis Alberto. A Escola Franciscana: de Boaventura a Ockham. Revista Veritas, PUCRS, v. 45, n. 3, set. 2000.

. Obras Escolhidas de São Boaventura. Edição bilíngue (Latim/Português). Porto Alegre: EST, SULINA E UCS, 1983. Nesta obra encontram-se os seguintes textos de São Boaventura: "Brevilóquio", "Itinerário da Mente para Deus", "Redução das Ciências à Teologia", "Cristo, Único Mestre de Todos", "Três Caminhos da Vida Espiritual ou Incêndio do Amor", "As Seis Asas do Serafim”, O Governo da Alma”, "Solilóquios sobre os Quatro Exercícios Mentais", "A Árvore da Vida", "A Perfeição da Vida", "Tratado de Preparação para a Missa", "Vinte e Cinco Memoriais sobre a Vida Espiritual", "Carta Sobre a Imitação de Cristo" e "As Cinco Festividades do Menino Jesus".

GILSON, Etienne. La filosofía de San Buenaventura. Tradução de Esteban de Zuraire, Buenos Aires: Editorial Desclée de Brouwer, 1948. (Colección Thau).

HEINZ-MOHR. Dicionário dos símbolos - imagens e sinais da arte cristã. São Paulo: Paulus, 1994.

PIAZZA, Leonardo. Mediazione simbolica in San Bonaventura. Vicenza: Edizioni L.I.E.F., 1978.

ULLMANN, Reinhold Aloysio. A universidade medieval. Porto Alegre: EDIPUCRS, 2000 .

Recebido: $17 / 06 / 2014$

Avaliado: 23/08/2014 